\section{Identification of Markers Linked to Seedlessness in Citrus kinokuni hort. ex Tanaka and Its Progeny Using Bulked Segregant Analysis}

\author{
Dario J. Chavez and José X. Chaparro ${ }^{1}$ \\ Horticultural Sciences Department, University of Florida, 1301 Fifield Hall, \\ Gainesville, FL 32611
}

Additional index words. seeded, seedless, breeding, MAS, RAPDs, Mukaku kishu

\begin{abstract}
Citrus kinokuni 'Mukaku kishu' PI539530 and its progeny were studied to identify random amplified polymorphic DNA (RAPD) primers associated with seedlessness. Ninety-one $F_{1}[($ Robinson op) $\times C$. kinokuni] individuals showed a 1:1 segregation ratio between seedless and seeded phenotypes with seedless as a single dominant gene. Bulked segregant analysis was used to identify markers associated with the seedless locus. Eighteen RAPD primers were mapped into a partial linkage group $(\approx 55.8 \mathrm{cM}$ length) with four RAPD primers flanking the seedless locus: OPAI11-0.8 at 8.7 cM, OPAJ19-1.0 at $8.4 \mathrm{cM}$, OPM06r-0.85 at $4.3 \mathrm{cM}$, and OPAJ04r-0.6 at $6.4 \mathrm{cM}$. The identification of molecular markers linked to $C$. kinokuni $F$ s seedless locus constitutes an important and major tool for citrus breeding and selection.
\end{abstract}

Seedless or low seed content is an important trait for fresh and processed citrus fruit in the United States and the world. Yamasaki et al. (2007) described how seedlessness in citrus can be produced by several factors, including selfincompatibility, male or female sterility, and early arrested seed after fertilization, all coupled with parthenocarpy. Similarly, Gmitter et al. (2009) described how ploidy manipulation by crossing tetraploid and diploid parents could produce seedless triploid hybrids.

Seedless citrus breeding and production constitutes a tedious and extensive effort that typically takes several years from breeding to cultivar release. Problems with seed production by cross-pollination, quantitative inheritance, production of stable polyploids, and generation of large progenies for selection are some of the constraints that a breeder has to overcome using current methods and techniques for seedless citrus improvement.

The seedless trait inherited as a single dominant gene has been used to breed seedless citrus in Japan. Crosses with C. kinokuni hort. ex Tanaka 'Mukaku kishu' have produced the seedless cultivars Southern Yellow, Kankitsu Chukanbohon Nou 6 Gou, and Kakitsu Chukanbohon Nou 5 Gou (Yamasaki et al., 2009; Yoshida et al., 2005a, 2005b).

Yamasaki et al. (2007) studied the factors controlling seedless expression in C. kinokuni

\footnotetext{
Received for publication 8 Feb. 2011. Accepted for publication 22 Mar. 2011

We thank Dr. James W. Olmstead for providing the random amplified polymorphic DNA primers for this experiment and an anonymous reviewer for his suggestions and commentaries for the completion of the manuscript.

${ }^{1}$ To whom reprint requests should be addressed; e-mail jaguey58@ufl.edu.
}

'Mukaku kishu'. 'Mukaku kishu' seedless is believed to be originated by a mutation from seedy C. kinokuni. 'Mukaku kishu' seedlessness was inherited in its progeny in a 1:1 ratio when crossed with seeded cultivars (Nesumi et al., 1992, 2001).

Seedlessness in C. kinokuni was proposed to be regulated by two genes, a $F s$ dominant gene and a $I s$ repressor gene that inhibits seedless expression, with the 'Mukaku kishu' genotype being Fsfs-isis (Yamasaki et al., 2007, 2009). It was reported that the seedless expression in 'Mukaku kishu' is produced probably by stenospermocarpy, which is characterized by early arrested development of the fertilized seeds, without endosperm abortion, and incomplete development of the seedcoat (Yamasaki et al., 2009).

Citrus kinokuni 'Mukaku kishu' has been widely used in crosses with seedy citrus advanced breeding lines at the Fruit Tree Breeding Program at the University of Florida, Gainesville, FL. Advanced progenies have been evaluated for the presence or absence of seeds, but the long juvenility period and biological constrains have delayed our selection. Genomic mapping identifies markers associated with traits of interest, permitting the use of markerassisted selection (MAS) for traits expressed in late development (Gulsen et al., 2010).

Bulked segregant analysis (BSA) is a rapid procedure used to efficiently identify markers associated with specific regions of the genome. Two pooled DNA samples composed of individuals having alternate states of a trait are generated and used to identify markers that distinguish them (Michelmore et al., 1991). Markers identified using BSA are typically closely linked to the target trait, usually within $20 \mathrm{cM}$ of the target locus.

Several traits in citrus have been mapped to specific genomic regions by using BSA.
The dwarfing gene in Poncirus trifoliata (L.) Raf. was linked to several RAPD markers (Cheng and Roose, 1995). The Citrus Tristeza Virus (CTV) resistance gene was flanked with two RAPD fragments at $17.8 \mathrm{cM}$ and $23.1 \mathrm{cM}$ interval regions (Cristofani et al., 1999). Resistance to citrus nematode was found in a $3.3 \mathrm{cM}$ interval region defined by three markers (Ling et al., 2000). Polyembryony locus in Citrus unshiu Marcow was flanked with markers in a refined linkage group region of $47 \mathrm{cM}$ (Nakano et al., 2008).

The purpose of this research was to identify the genomic region associated with seedlessness in $C$. kinokuni and its progeny by using BSA. Specific objectives of this research included the confirmation of the monogenic inheritance of seedlessness and identification of RAPD markers closely linked to this genomic region.

\section{Materials and Methods}

Plant material. A breeding selection 'GS' obtained from open-pollinated progeny of Robinson tangerine was used as the female parent in crosses with Citrus kinokuni 'Mukaku kishu' PI539530 at the Fruit Tree Breeding Program at the University of Florida, Gainesville, FL. A population of $\approx 373 \mathrm{~F}_{1}$ hybrids was obtained, planted, and grown in Gainesville, FL. Plants were maintained using standard conventional cultural practices and fertility rates for citrus production.

Inheritance study. Fruit production in the $\mathrm{F}_{1}$ hybrids was evaluated for a period of 3 to 5 years after planting. A total of $91 \mathrm{~F}_{1}$ hybrids (out of 373) produced fruit and were evaluated in two to three fruits per plant per year for at least 2 to 3 years (Fig. 1). For our study, the seedless allele was denoted as $F s$ and the seeded allele as $f s$. We did not include the $I s$ repressor gene in our model because the segregation ratio was not consistent with ' $G S$ ' being heterozygous for the $I s$ gene. Notations followed previous descriptions for seedlessness in $C$. kinokuni (Yamasaki et al., 2007, 2009).

DNA isolation. DNA was extracted from leaf tissue using a modified CTAB method (Blaker, 2010). Leaf tissue (30 mg) of each sample was added to 2-mL Eppendorf microcentrifuge tubes with three 5-mm stainless steel beads, $750 \mu \mathrm{L}$ of CTAB buffer $(2 \%$ CTAB, $100 \mathrm{~mm}$ Tris $\mathrm{pH} 8.0,1.4 \mathrm{M} \mathrm{NaCl}, 0.5 \mathrm{M}$ EDTA, 1\% PVP) previously mixed with mercaptoethanol $\left(1 \mu \mathrm{L} \cdot \mathrm{mL}^{-1}\right)$, and $8 \mu \mathrm{L}$ of RNAse $\left(10 \mathrm{mg} \cdot \mathrm{mL}^{-1}\right)$. Samples were grounded two to three times at $30 \mathrm{~Hz}$ in a Tissue Lyser (Qiagen Inc., Valencia, CA) for 1.5 min until tissue clumps were not visible. Samples were vortexed and incubated in a $65^{\circ} \mathrm{C}$ water bath for $6 \mathrm{~min}$. Then, tubes were vortexed and a volume of $750 \mu \mathrm{L}$ of chloroform:isoamyl (24:1) was added. Tubes were vortexed, incubated at $-20^{\circ} \mathrm{C}$ for $6 \mathrm{~min}$, and then centrifuged at $12,000 \mathrm{rcf}$ for $10 \mathrm{~min}$. The aqueous phase was transferred to a new $2-\mathrm{mL}$ centrifuge tube, and $500 \mu \mathrm{L}$ of cold isopropanol was added. Tubes were gently mixed, incubated at $-20^{\circ} \mathrm{C}$ for $6 \mathrm{~min}$, and then centrifuged at $16100 \mathrm{rcf}$ for $10 \mathrm{~min}$. Supernatant was removed and the pellet was washed 


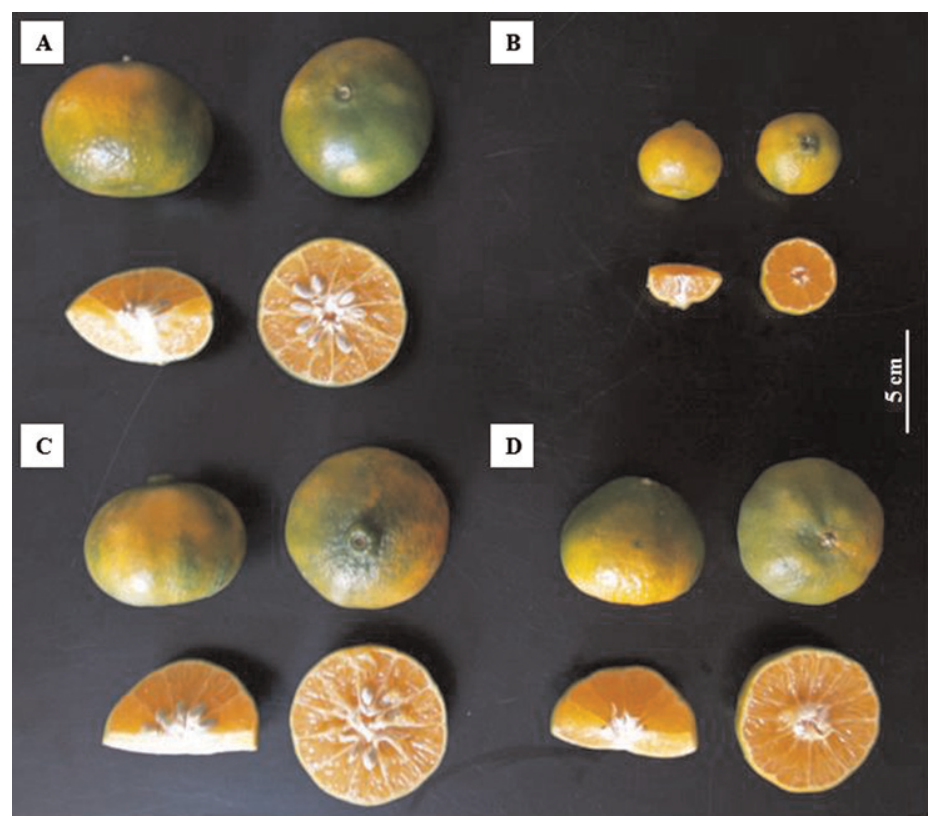

Fig. 1. Fruit of (A) 'GS' (Robinson OP), (B) Citrus kinokuni 'Mukaku kishu', (C) a seeded $\mathrm{F}_{1}$ hybrid ('GS' $\times$ C. kinokuni), and (D) a seedless $\mathrm{F}_{1}$ hybrid ('GS' $\times$ C. kinokuni).

with $500 \mu \mathrm{L}$ of cold $70 \%$ EtOH (by inverting the tubes carefully). Tubes were incubated at $-20^{\circ} \mathrm{C}$ for $5 \mathrm{~min}$ and then centrifuged at 16,100 ref for $5 \mathrm{~min}$. Supernatant was removed, and the pellet was washed with $500 \mu \mathrm{L}$ of cold $90 \%$ EtOH (repeating mixing, incubation, and centrifugation as described before). Ethanol was poured off and the pellet was dried at bench top for $\approx 30$ to $45 \mathrm{~min}$ (room temperature). The pellet DNA was resuspended in $50 \mu \mathrm{L}$ TE buffer (10 mm Tris- $\mathrm{HCl}, 0.1 \mathrm{~mm}$ EDTA) and $50 \mu \mathrm{L}$ of deionized $\mathrm{H}_{2} \mathrm{O}$. DNA concentration was quantified in a UV10 Spectrophotometer (Thermo Scientific, Waltham, MA). DNA concentration for all the samples was standardized to $20 \mathrm{ng} \cdot \mu \mathrm{L}^{-1}$.

Polymerase chain reaction protocol. Polymerase chain reaction (PCR) products were amplified in $12 \mu \mathrm{L}$ volume reaction containing $2 \mu \mathrm{L}$ of $20 \mathrm{ng} \cdot \mu \mathrm{L}^{-1}$ DNA template, $2.25 \mu \mathrm{L}$ $10 \times$ ThermoPol Reaction Buffer $[10 \mathrm{~mm} \mathrm{KCl}$, $10 \mathrm{~mm}\left(\mathrm{NH}_{4}\right)_{2} \mathrm{SO}_{4}, 20 \mathrm{~mm}$ Tris- $\mathrm{HCl}, 2 \mathrm{~mm}$ $\mathrm{MgSO}_{4}, 0.1 \%$ Triton X-100, pH 8.8 at $\left.25^{\circ} \mathrm{C}\right]$, $1 \mu \mathrm{L} 20 \mu \mathrm{M}$ primer, $1 \mu \mathrm{L} 2.5 \mathrm{~mm}$ dNTPs, $0.2 \mu \mathrm{L}$ Taq DNA polymerase, and $6.5 \mu \mathrm{L}$ DNA grade water. PCR parameters were $5 \mathrm{~min}$ at $94{ }^{\circ} \mathrm{C}$ followed by 40 cycles of $1 \mathrm{~min}$ at $94{ }^{\circ} \mathrm{C}$, $1 \mathrm{~min}$ at $43^{\circ} \mathrm{C}$, and $2 \mathrm{~min}$ at $72^{\circ} \mathrm{C}$, ending with $5 \mathrm{~min}$ at $72{ }^{\circ} \mathrm{C}$. PCR products were separated on $1.5 \%(\mathrm{~m} / \mathrm{v})$ agarose gel. Gels were stained with ethidium bromide and recorded using a digital gel documentation system.

Gels were scored based on presence or absence of bands with $1=$ presence and $0=$ absence. The band scoring patterns for each primer and locus were used as phenotypes (scoring phenotypes) for comparisons with the expected presence and absence of our desired alleles, $F_{S}$ and $f_{S}$ from both $C$. kinokuni and ' $\mathrm{GS}$ ', in the $\mathrm{F}_{1}$ progeny

Bulked segregant analysis. The experiment was divided into three stages. In Stage 1, DNA of 'GS', C. kinokuni, bulk of 19 seedless and bulk of 11 seeded $F_{1}$ hybrids was screened with 1200 RAPDs (Ops series: A, B, C, D, E, F, G, H, I, J, K, L, M, N, O, P, Q, R, S, T, U, V, W, X, $\mathrm{Y}, \mathrm{Z}, \mathrm{AA}, \mathrm{AB}, \mathrm{AC}, \mathrm{AD}, \mathrm{AE}, \mathrm{AF}, \mathrm{AG}, \mathrm{AH}, \mathrm{AI}$, AJ, AK, AL, AM, AN, AO, AP, AQ, AR, AS, AT, AU, AV, AW, AX, AY, AZ, BA, BB, BC, $\mathrm{BD}, \mathrm{BE}, \mathrm{BF}, \mathrm{BG}, \mathrm{BH} ; 10$ base-pairs long; Operon Technologies Inc., Alameda, CA). Bulks of seedless and seeded $F_{1}$ hybrids contained equal pooled quantities of DNA as described by Michelmore et al. (1991) (Fig. 2A).

In Stage 2, a total of 199 RAPD primers considered as putatively associated with seedless allele $F s$ from $C$. kinokuni and with seeded allele $f_{S}$ from $C$. kinokuni and 'GS' was rescreened on a set of three seedless and three seeded $\mathrm{F}_{1}$ hybrids (Fig. 2B).

In Stage 3, 53 RAPD primers associated with seedless allele $F s$ and seeded allele $f_{s}$ were screened with DNA of 'GS', C. kinokuni, and a population of $91 \mathrm{~F}_{1}$ hybrids to map the genomic region associated with the seedless trait of interest (Fig. 2C).

Data analysis. The chi-square "goodnessof-fit" test was used to test fit of the expected 1:1 Mendelian segregation ratios for seedlessness and the molecular markers in the $F_{1}$ progeny. Association of the seedless locus and the RAPD primer phenotypes were compared using a chi-square "test of independence" with a significance level of 5\%. Data analysis was performed using FREQ procedure of SAS (Statistical Analysis System Version 9.1; SAS Institute, Cary, NC). In the chi-square "test of independence," each band was considered an observation with two possible responses: presence or absence, and each plant was considered an observation with two possible responses: seedless or seeded. The null hypothesis of the chi-square "test of independence" was that the ratio of presence/ seeded, presence/seedless, absence/seeded, and absence/seedless was a 1:1:1:1 segregation ratio.

Linkage analysis between molecular markers and seedlessness were performed using JoinMap Version 3.0 software (Plant Research International, Wageningen, The Netherlands; Van Ooijen, 2006) using a likelihood of odds (LOD) score of 10.0, a recombination fraction of 0.5 , and Kosambi's mapping function.

\section{Results and Discussion}

Fruit of $91 \mathrm{~F}_{1}$ hybrids were evaluated in the fall of 2009 and 2010 for presence or absence of seeds (Fig. 1). The phenotype of seedless and seeded individuals was consistent between the 2 years during fruit evaluations in 2009 and 2010 ( $t$ test, $P=1.00$ ). The number of seedless and seeded $F_{1}$ progeny was 43 and 48, respectively. The observed segregation ratio was not significantly different from the expected 1:1 segregation ratio with a chi-square "goodness of fit" of $\chi^{2}=$ 0.88 . The seedless locus from $C$. kinokuni was previously described as a single dominant gene (Nesumi et al., 1992, 2001). Our results confirmed the previously proposed $F s f s$ genotype of C. kinokuni and indicate that the genotype of 'GS' is $f s f s$ (Yamasaki et al., 2007, 2009). The segregation data does not support the presence of the $I s$ repressor allele in this population. Of the 1200 RAPD primers screened, $70(5.8 \%)$ and $115(9.6 \%)$ primers amplified fragments present in C. kinokuni, absent in 'GS', and polymorphic between the seedless and seeded bulks, respectively (Fig. 2A; Table 1).

The first screen identified 185 RAPD primers producing markers potentially linked to the seedless locus. The potential markers from the primary screen were rescreened on three seedless and three seeded $F_{1}$ individuals. This secondary screen identified 53 markers putatively linked to the $F_{S}$ locus (Fig. 2B; Table 2). Of these, 28 RAPD markers appeared to be associated with the $f s$ allele and 25 RAPD markers associated with $F s$ allele from $C$. kinokuni. Almost $75 \%$ of the RAPD primers from the original screen were removed from our experiment as a result of lack of reproducibility and association with the DNA of seedless and seeded $F_{1}$ hybrids.

Fifty-three RAPD markers putatively associated with $F s$ and $f_{S}$ alleles were used to amplify DNA of 'GS', C. kinokuni, and $91 \mathrm{~F}_{1}$ hybrid individuals (Fig. 2C). A linkage map with 18 RAPD markers covering $\approx 55.8 \mathrm{cM}$ was obtained with a LOD of 10.0 (Fig. 3). Ten RAPD markers associated with the Fs (seedless) allele and eight RAPD markers with the $f_{S}$ (seeded) allele from $C$. kinokuni were identified (Table 3).

The segregation data for the 18 RAPD markers linked to the $F_{S}$ locus did not deviate significantly from the expected 1:1 segregation ratio $\left(\chi^{2}<3.84\right)$ (Table 4$)$. As expected, the 18 RAPD markers did not segregate independently from the seedless locus (chi-square "test of independence," $\chi^{2}>3.84$ ) (Table 4). Markers OPAI11-0.8, OPAJ19-1.0, OPM06r-0.85, and OPAJ04r-0.6 were mapped to $8.7 \mathrm{cM}$, 

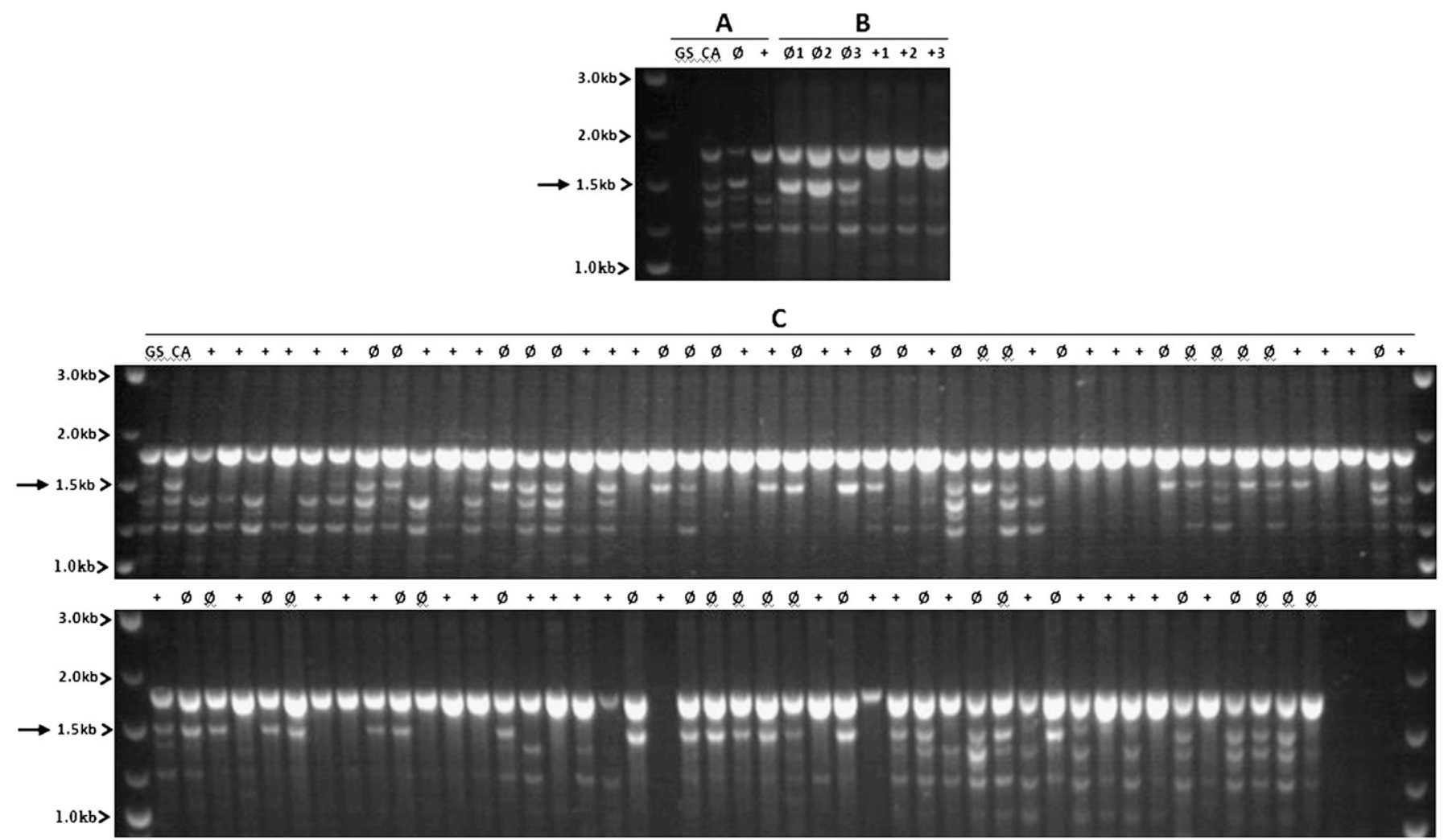

Fig. 2. Segregation pattern of random amplified polymorphic DNA (RAPD) marker OPS01-1.5 associated with the seedless allele $F s$ from $C$. kinokuni PI539530. (A) Bulked segregant analysis of 'GS' (Robinson OP, seeded), Citrus kinokuni 'PI539530' (CA, seedless), bulk of 19 seedless $F_{1}$ hybrids (Ø), and bulk of 11 seeded $\mathrm{F}_{1}$ hybrids $(+)$. (B) Rescreen with three seedless $\mathrm{F}_{1}$ hybrids $(\varnothing 1, \varnothing 2, \varnothing 3)$ and three seeded $\mathrm{F}_{1}$ hybrids $(+1,+2,+3)$. (C) Screen of 'GS' (Robinson OP, seeded), C. kinokuni (CA, seedless), and $91 \mathrm{~F}_{1}$ hybrids $(\varnothing=$ seedless, $+=$ seeded). Arrow indicates the location of marker OPS01-1.5. Lanes 1 and 50 and Lanes 2 to 49 contain $1 \mathrm{~kb}$ ladder standard and 'GS' $\times$ C. kinokuni RAPD products, respectively.

Table 1. Bulked segregant analysis (BSA) screening of 1200 RAPD primers for seedlessness using breeding selection 'GS' (Robinson OP, seeded), Citrus kinokuni PI539530 (CA, seedless), bulk of seedless $\mathrm{F}_{1}$ hybrids $(\mathrm{GS} \times$ C. kinokuni, $\mathrm{n}=19)$ plants $(\varnothing)$, and bulk of seeded $\mathrm{F}_{1}$ hybrids ('GS' $\times C$. kinokuni, $\mathrm{n}=11$ ) plants $(+)^{\mathrm{z}}$

\begin{tabular}{|c|c|c|c|c|c|c|c|}
\hline \multirow[b]{2}{*}{ Allele ${ }^{y}$} & \multicolumn{4}{|c|}{ Phenotypes } & \multirow[b]{2}{*}{ Loci (no) $)^{\mathrm{x}}$} & \multirow[b]{2}{*}{ Primers (no.) ${ }^{\mathrm{w}}$} & \multirow{2}{*}{$\begin{array}{c}\text { Percentage total } \\
(\%)^{\mathrm{v}}\end{array}$} \\
\hline & GS & $\mathrm{CA}$ & $\varnothing$ & + & & & \\
\hline Seeded $f_{s}$ & 1 & 0 & 0 & 1 & 20 & 14 & 1.2 \\
\hline Seeded $f_{s}$ & 0 & 1 & 0 & 1 & 166 & 115 & 9.6 \\
\hline Seedless $F S$ & 0 & 1 & 1 & 0 & 83 & 70 & 5.8 \\
\hline & & & & Total & 269 & 199 & 16.6 \\
\hline
\end{tabular}

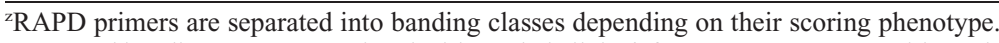

'Expected banding pattern associated with seeded allele $f_{s}$ from ' $G S$ ' $=1-0-0-1$, with seeded allele $f_{s}$ from $C$. kinokuni $=0-1-0-1$, and with seedless allele $F$ f from $C$. kinokuni $=0-1-1-0$. Score of $1=$ presence and $0=$ absence of a band.

${ }^{x}$ Number of polymorphic polymerase chain reaction fragments associated with each trait.

wNumber of RAPD primers yielding polymorphisms.

"Percentage of primers producing polymorphisms.

$\mathrm{RAPD}=$ random amplified polymorphic DNA

Table 2. Rescreen of 199 putative RAPD markers using three seedless $(\varnothing 1, \varnothing 2, \varnothing 3)$ and three seeded $(+1$, $+2,+3) \mathrm{F}_{1}$ hybrids ('GS' $\times$ C. kinokuni). ${ }^{2}$

\begin{tabular}{|c|c|c|c|c|c|c|c|c|c|}
\hline \multirow[b]{2}{*}{ Allele ${ }^{y}$} & \multicolumn{6}{|c|}{ Phenotypes } & \multirow[b]{2}{*}{ Loci $(\text { no. })^{x}$} & \multirow[b]{2}{*}{ Primers (no.) ${ }^{\mathrm{w}}$} & \multirow{2}{*}{$\begin{array}{c}\text { Percentage total } \\
(\%)^{\mathrm{v}}\end{array}$} \\
\hline & $\overline{\emptyset 1}$ & $\varnothing 2$ & $\varnothing 3$ & +1 & +2 & $\overline{+3}$ & & & \\
\hline Seeded & 0 & 0 & 0 & 1 & 1 & 1 & 31 & 28 & 14.1 \\
\hline Seedless & 1 & 1 & 1 & 0 & 0 & 0 & 25 & 25 & 12.6 \\
\hline \multicolumn{7}{|c|}{ Total } & 56 & 53 & 26.7 \\
\hline
\end{tabular}

${ }^{2}$ RAPD markers are separated into banding classes depending on their scoring phenotype.

'Banding pattern associated with seeded allele $f_{S}$ from 'GS' and $C$. kinokuni $=0-0-0-1-1-1$, and with seedless allele $F$ f from $C$. kinokuni $=1-1-1-0-0-0$. Score of $1=$ presence and $0=$ absence of a band.

${ }^{x}$ Number of markers associated with each trait.

"Number of RAPD primers associated with each trait.

"Percentage of primers associated with each trait out of the rescreened 199 putative RAPDs.

$\mathrm{RAPD}=$ random amplified polymorphic DNA.
$8.4 \mathrm{cM}, 4.3 \mathrm{cM}$, and $6.4 \mathrm{cM}$ from the $F s$ locus, respectively (Fig. 3). These four primers had a recombination frequency 0.10 or less and a LOD score greater than 14.0 with the seedless locus $F$ s in C. kinokuni (Table 5).

BSA constituted a rapid and efficient method for the generation of a localized linkage map of the seedless locus genomic region. Similar results have been reported for the identification of genomic regions associated with other traits of interest in citrus: dwarfing gene in $P$. trifoliata, CTV resistance gene, citrus nematode resistance, polyembryony locus in C. unshiu, etc. (Cheng and Roose, 1995; Cristofani et al., 1999; Ling et al., 2000; Nakano et al., 2008).

MAS for seedless citrus using OPAI11-0.8, OPAJ19-1.0, OPM06r-0.85, and OPAJ04r will allow us to identify progeny carrying the seedless locus and to rapidly distribute this gene(s) in our citrus breeding lines. Seedless individuals could be selected as young seedlings in the greenhouse. Mohan et al. (1999) described the importance of MAS and BSA in accelerating the mapping and improvement of many genes in different plant species.

One of the problems associated with MAS is the presence of false-positives resulting from recombination between the markers and the trait of interest (Mohan et al., 1999). In our study, we identified four RAPD markers within $9 \mathrm{cM}$ of the seedless locus in C. kinokuni. We expect a reduction in the number of 


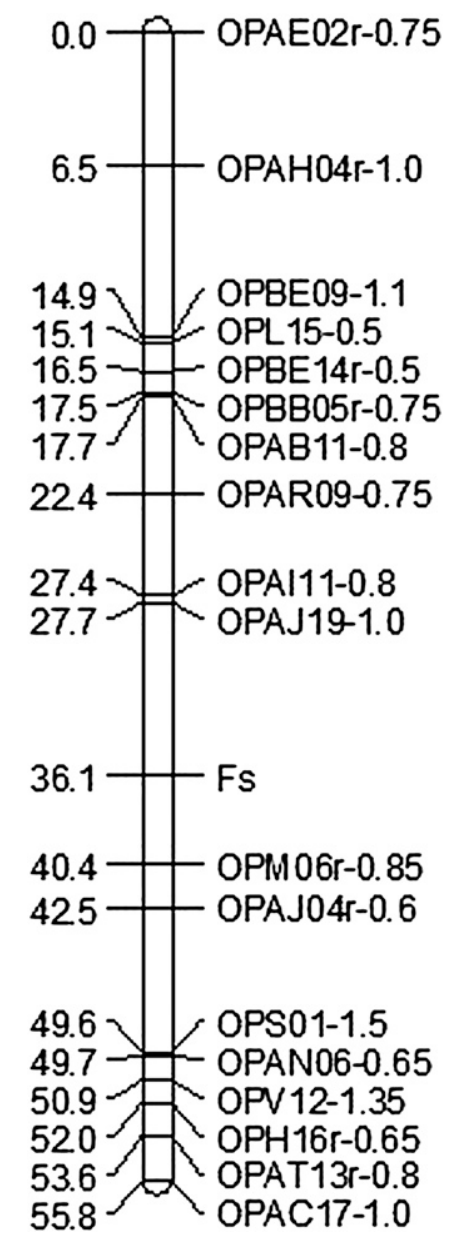

Fig. 3. Partial linkage map of a population of 'GS' $\times$ C. kinokuni PI539530 of random amplified polymorphic DNA primers with a threshold likelihood of odds score 10. Map of the seedless locus Fs. Genetic distance (cM) between markers is presented on the left side of the linkage map using Kosambi's mapping function. Primer names are shown on the right by the operon primer code, linkage phase (r, repulsion), and fragment size in kb. Markers showing distorted segregation were not included.

Table 3. Genotyping of 53 RAPD markers potentially linked to seedlessness using 'GS', Citrus kinokuni, and $91 \mathrm{~F}_{1}$ hybrids ('GS' $\times$ C. kinokuni). ${ }^{\mathrm{z}}$

\begin{tabular}{lc}
\hline Alleles & Primers (no.) \\
\hline Seedless $F$ s from $C$. kinokuni & 10 \\
Seeded $f$ s from $C$. kinokuni & 8 \\
Seeded $f$ from GS & 0 \\
Not linked & 21 \\
Not repeatable & 14 \\
\hline
\end{tabular}

${ }^{2}$ RAPD markers are separated into classes depending on their allele association.

$\mathrm{RAPD}=$ random amplified polymorphic DNA.

false-positives/-negatives using the four RAPD markers flanking the seedless locus. The probability of a double crossover event between the markers and the seedless locus is low compared with that of a single crossover between them. Cristofani et al. (1999) reported the importance of using several RAPD markers flanking the CTV resistance gene for selection
Table 4. Segregation of random amplified polymorphic DNA markers associated with the seedless locus of Citrus kinokuni in the 'GS' $\times$ C. kinokuni $\mathrm{F}_{1}$ population.

\begin{tabular}{lccccc}
\hline Primer $^{2}$ & $\begin{array}{c}\text { Band } \\
\text { present }\end{array}$ & $\begin{array}{c}\text { Band } \\
\text { absent }\end{array}$ & $\begin{array}{c}\text { Missing } \\
\text { data }\end{array}$ & $\begin{array}{c}\chi^{2} \text { goodness-of- } \\
\text { fit test }\end{array}$ & $\begin{array}{c}\chi^{2} \text { test of } \\
\text { independence }\end{array}$ \\
\hline OPAE02r-0.75 & 47 & 44 & 0 & 0.1 Ns & $10.2^{* *}$ \\
OPAH04r-1.0 & 47 & 44 & 0 & 0.1 & 15.4 \\
OPBE09-1.1 & 44 & 42 & 5 & 0.0 & 30.3 \\
OPL15-0.5 & 47 & 44 & 0 & 0.1 & 31.9 \\
OPBE14r-0.5 & 45 & 43 & 3 & 0.0 & 33.4 \\
OPBB05r-0.75 & 44 & 43 & 4 & 0.0 & 32.9 \\
OPAB11-0.8 & 47 & 44 & 0 & 0.1 & 36.7 \\
OPAR09-0.75 & 46 & 44 & 1 & 0.0 & 45.7 \\
OPAI11-0.8 & 47 & 44 & 0 & 0.1 & 58.9 \\
OPAJ19-1.0 & 45 & 44 & 2 & 0.0 & 60.2 \\
OPM06r-0.85 & 47 & 44 & 0 & 0.1 & 72.2 \\
OPAJ04r-0.6 & 51 & 44 & 0 & 0.5 & 60.0 \\
OPS01-1.5 & 46 & 44 & 1 & 0.0 & 48.5 \\
OPAN06-0.65 & 47 & 44 & 0 & 0.1 & 46.6 \\
OPV12-1.35 & 46 & 44 & 1 & 0.0 & 43.2 \\
OPH16r-0.65 & 46 & 42 & 3 & 0.2 & 38.8 \\
OPAT13r-0.8 & 44 & 43 & 4 & 0.0 & 39.3 \\
OPAC17-1.0 & 45 & 43 & 3 & 0.0 & 34.8 \\
\hline
\end{tabular}

${ }^{\text {ZPrimer names are indicated by the operon primer code, linkage phase }(\mathrm{r}=\text { repulsion}) \text {, and fragment size }}$ in $\mathrm{kb}$.

NS = non-significant. Chi-square values for all the primers were not significantly different from expected $1: 1$ segregation ratios, $\mathrm{df}=1, \alpha=0.05$.

$* *$ Chi-square values for all primers did not assort independently from the seedless locus, $\mathrm{df}=3$, $\alpha=0.01$.

Table 5. Recombination frequency and likelihood of the odds (LOD) score for random amplified polymorphic DNA primers associated with seedless locus in the $\mathrm{F}_{1}$ population from ' $\mathrm{GS}$ ' $\times$ Citrus kinokuni PI539530.

\begin{tabular}{lcc}
\hline Primer $^{z}$ & $\begin{array}{c}\text { Recombination } \\
\text { frequency }\end{array}$ & LOD \\
\hline OPAR09-0.75 & 0.14 & 10.95 \\
OPAI11-0.8 & 0.10 & 14.63 \\
OPAJ19-1.0 & 0.09 & 15.18 \\
OPM06r-0.85 & 0.06 & 19.01 \\
OPAJ04r-06 & 0.07 & 17.92 \\
OPS01-1.5 & 0.13 & 11.80 \\
OPAN06-0.65 & 0.14 & 11.29 \\
OPV12-1.35 & 0.16 & 10.37 \\
\hline
\end{tabular}

${ }^{\mathrm{z}}$ Primer names are indicated by the operon primer code, linkage phase (r, repulsion), and fragment size in $\mathrm{kb}$.

when identifying CTV-resistant progeny in $C$. sunki and $P$. trifoliata hybrids.

In conclusion, BSA constituted a rapid method to identify the genomic region associated with the seedless locus. We have confirmed that the seedless locus originating from C. kinokuni is controlled by a single dominant allele and a total of 18 RAPD markers were mapped to a partial linkage group. Four RAPD markers, OPAI11-0.8, OPAJ19-1.0, OPM06r0.85 , and OPAJ04r-0.6, were identified within $9 \mathrm{cM}$ of the seedless locus (Fig. 3). MAS of seedless individuals by the four RAPD markers, OPAI11-0.8, OPAJ19-1.0, OPM06r0.85 , and OPAJ04r-0.6, would reduce the probability of some false-positives/-negatives. Conversion of RAPD markers to sequence characterized amplified region-type markers is being pursued. The identification of RAPD markers associated with seedlessness from C. kinokuni constitutes an important tool for citrus breeding that could change and accelerate the breeding of seedless cultivars.

\section{Literature Cited}

Blaker, K. 2010. Detection of seed dormancy QTL in three $F_{2}$ populations of peach. MS thesis, University of Florida.

Cheng, F.S. and M.L. Roose. 1995. Origin and inheritance of dwarfing by the citrus rootstock Poncirus trifoliata 'Flying Dragon'. J. Amer. Soc. Hort. Sci. 120:286-291.

Cristofani, M., M.A. Machado, and D. Grattapaglia. 1999. Genetic linkage maps of Citrus sunki Hort. ex. Tan. and Poncirus trifoliata (L.) Raf. and mapping of Citrus Tristeza Virus resistance genes. Euphytica. 109:25-32.

Gmitter, F.G., Jr., J.R. Soneji, and M.N. Rao. 2009 Citrus breeding, p. 105-132. In: Jain, S.M. and P.M. Priyadarshan (eds.). Breeding plantation tree crops: Temperate species. Springer-Verlag, Berlin, Germany.

Gulsen, O., A. Uzun, I. Canan, U. Seday, and E. Canihos. 2010. A new citrus linkage map based on SRAP, SSR, ISSR, POGP, RGA, and RAPD markers. Euphytica 173:265-277.

Ling, P., L.W. Duncan, Z. Deng, D. Dunn, X. Hu, S. Huang, and F.G. Gmitter, Jr. 2000. Inheritance of citrus nematode resistance and its linkage with molecular markers. Theor. Appl. Genet. 100:1010-1017.

Michelmore, R.W., I. Paran, and R.V. Kesseli. 1991. Identification of markers linked to diseaseresistance genes by bulked segregant analysis: A rapid method to detect markers in specific genomic regions by using segregating populations. Proc. Natl. Acad. Sci. USA. 88:9828-9832.

Mohan, M., S. Nair, A. Bhagwat, T.G. Krishna, M. Yano, C.R. Bhatia, and T. Sasaki. 1999. Genome mapping, molecular markers and markerassisted selection in crop plants. Mol. Breed. 3:87-103.

Nakano, M., T. Shimizu, T. Kuniga, H. Nesumi, and M. Omura. 2008. Mapping and haplotyping of the flanking region of the polyembryony locus in Citrus unshiu Marcow. J. Jpn. Soc. Hort. Sci. 77:109-114.

Nesumi, H., Y. Ito, T. Yoshioka, and T. Yoshida. 1992. Female sterility of 'Mukakukishu' and its inheritance. J. Jpn. Soc. Hort. Sci. 61(Suppl. 1): 36-37 [in Japanese]. 
Nesumi, H., M. Nakano, and T. Yoshida. 2001. Mode of inheritance on the abnormal development of impregnated ovules derived from Mukaku-kishu. J. Jpn. Soc. Hort. Sci. 70(Suppl. 2):403 (abstr.) [in Japanase].

Van Ooijen, J.W. 2006. JoinMap® ${ }^{\circledR}$ 4.0, software for the calculation of genetic linkage maps in experimental populations. Kyazma, B.V., Wageningen, The Netherlands.

Yamasaki, A., A. Kitajima, N. Ohara, M. Tanaka, and K. Hasegawa. 2007. Histological study of expression of seedlessness in Citrus kinokuni 'Mukaku Kishu' and its progenies. J. Amer. Soc. Hort. Sci. 132:869-875.

Yamasaki, A., A. Kitajima, N. Ohara, M. Tanaka, and K. Hasegawa. 2009. Characteristics of arrested seeds in Mukaku Kishu-type seedless citrus. J. Jpn. Soc. Hort. Sci. 78(Suppl. 1):61-67.

Yoshida, T., H. Nesumi, T. Yoshioka, Y. Ito, I. Ueno, and Y. Yamada. 2005a. 'Kankitsu Chukanbohon Nou 5 Gou' ('Citrus Parental Line Norin No. 5') is useful for breeding seedless and early maturing cultivars. Bul. Natl. Inst. Fruit Tree Sci. 4:47-52 [in Japanese with English abstract].

Yoshida, T., H. Nesumi, T. Yoshioka, Y. Ito, M. Yano, M. Nakano, I. Ueno, Y. Yamada, K. Ogawa, S. Murase, F. Takishita, T. Hidaka, and S. Kawai. 2005b. 'Kankitsu Chukanbohon Nou 6 Gou' ('Citrus Parental Line Norin No. 6') is useful for breeding seedless and functional componentrich cultivars. Bul. Natl. Inst. Fruit Tree Sci. 4:5359 [in Japanese with English abstract]. 